\title{
Structural and textural characterisation of NiMo catalysts supported on various zeolites
}

\author{
Zenon Sarbak ${ }^{1}$, Grażyna Fabiś ${ }^{2}$, Sławomir Binkowski ${ }^{1}$ \\ ${ }^{1}$ Laboratory of Adsorption and Catalysis, Faculty of Chemistry, Adam Mickiewicz University, Poznań, Poland, \\ e-mail:sarbak@amu.edu.pl \\ ${ }^{2}$ Institute of Coal Chemistry, Polish Academy of Science, Gliwice, Poland
}

\begin{abstract}
Structural and textural properties of nickel-molybdenum catalysts supported on four various type of zeolites of different chemical composition and porous structure have been studied by the methods of IR, XRD and the low-temperature sorption of nitrogen. The catalysts have been obtained by the two-stage impregnation of the supports with the solutions of nickel and molybdenum salts by the method of incipient wetness. The catalysts have been shown to preserve the structure characteristic of the appropriate zeolite supports.
\end{abstract}

Keywords: Zeolites, NiMo catalysts, structural properties, surface area, porosity.

\section{INTRODUCTION}

The NiMo catalysts deposited on acidic supports represent typical catalysts used for catalytic hydrocracking. They are bifunctional of hydrogenating-dehydrogenating and acidic properties. The metallic centres in the hydrocracking catalysts increase the rate of hydrogenation reaction, while the Brønsted acidic centres activate the reaction of catalytic cracking. The hydrogenation reaction can be activated by noble metals $(\mathrm{Pt}, \mathrm{Pd})$ or group 6 transition metals $(\mathrm{Mo}, \mathrm{W})$ in combination with group 9 metals $(\mathrm{Co})$ and group 10 metals $(\mathrm{Ni})$. The NiMo supports most often used are amorphous or crystalline aluminosilicates (zeolites). Among different functions of supports in catalytic processes their most important role is to ensure proper dispersion and stabilisation of the active components over large surfaces. The support should also provide the lowest possible resistance to the reagent diffusing into the active centres thanks to its properly chosen porous structure. The most commonly applied methods of the NiMo phase deposition include the impregnation with water solutions of metal salts followed by calcination. The conditions of impregnation and calcination are adjusted so that the introduction of the metallic phase into the zeolite would cause minimum changes in its texture and acidity and to ensure the best possible dispersion of the NiMo phase ${ }^{\mathbf{1 , 2}}$.

\section{EXPERIMENTAL}

\section{Catalysts preparation}

The catalysts supports were the commercially available synthetic zeolites: NaX produced by the Inowrocław Sodium Factory in, NaY and Ultrazet (UZ is a pentasil type zeolite) produced by the Institute of Industrial Chemistry in Warsaw and Na-mordenite (NaM) from Norton Company. At the first stage of preparation the zeolites were converted into the $\mathrm{H}$-form active in cracking by subjecting them to a solution of ammonium nitrate $\left(\mathrm{NH}_{4} \mathrm{NO}_{3}\right)$ at $90^{\circ} \mathrm{C}$ for 2 hours, drying at $110^{\circ} \mathrm{C}$ for 6 hours and then calcined at $450^{\circ} \mathrm{C}$ for 18 hours. Nickel and molybdenum ions were deposited in two stages by the method of incipient wetness. The first stage was the impregnation with Mo ions with the use of water solution of ammonia heptamolybdate $\left(\mathrm{NH}_{4}\right)_{6} \mathrm{Mo}_{7} \mathrm{O}_{24}$, while the second was the impregnation with the solution of nickel nitrate $\mathrm{Ni}\left(\mathrm{NO}_{3}\right)_{2}$.
After impregnation and calcination the samples were dried and calcined in the impregnation procedure were subjected to following physicochemical studies.

\section{Elemental analysis}

Elemental composition was determined by X-Ray Fluorescence (XRF) on a spectrometer Philips PW 2400, using the scintillation detector, proportional flow-through a detector $\left(\mathrm{Ar} / \mathrm{CH}_{4}\right)$ and a proportional sealed detector $(\mathrm{Xe})$. The samples were prepared by melting or pressing.

\section{X-Ray diffraction study}

$\mathrm{X}$-Ray diffraction patterns of the samples studied were taken on a diffractometer TUR M-62 with $\mathrm{CuK} \alpha$ $(\lambda=1,5418 \AA)$ radiation, generated at the voltage $30 \mathrm{KV}$ at the current of $25 \mathrm{~mA}$, transmitted through a nickel filter.

\section{IR study}

IR spectra were recorded on a Perkin-Elmer 180 spectrometer, in the range $4000-400 \mathrm{~cm}^{-1}$ with a resolution of $2 \mathrm{~cm}^{-1}$ for the samples in the form of a disc made of $1.5 \mathrm{mg}$ of the sample with $30 \mathrm{mg}$ of potassium bromide.

\section{Surface area, pore size and pore volume determination}

The surface area and the porous structure of the samples were determined by the method based on the lowtemperature $\left(-197^{\circ} \mathrm{C}\right)$ sorption of nitrogen at the Micrometrics ASAP 2010 apparatus. On the basis of the equilibrium pressures recorded in the range 0.0 do 1.0 the adsorption-desorption isotherms were drawn. The surface area was calculated from the BET (BrunauerEmmett-Teller) equation for the relative pressure $\left(\mathrm{p} / \mathrm{p}_{\mathrm{o}}\right)$ range 0.05 to 0.3 . The mean pore radius and the mean pore volume were calculated and the pore volume distribution was established on the basis of the BJH (BarretJoyner-Halenda) theory.

\section{RESULTS AND DISCUSSION}

Table 1 presents the chemical composition of the supports and NiMo catalysts determined by the XRF method, expressed in terms of appropriate oxides. As we can see UZ zeolite is a high-silica material characterised by the $\mathrm{SiO}_{2} / \mathrm{Al}_{2} \mathrm{O}_{3}$ ratio of 234 , whereas $\mathrm{NaX}$ and $\mathrm{NaY}$ are low- 
Table 1. The chemical composition of zeolite and the supported NiMo catalysts

\begin{tabular}{|l|c|c|c|c|c|c|c|c|}
\hline \multirow{2}{*}{ Component } & \multicolumn{9}{|c|}{ Composition (mass.\%) } \\
\cline { 2 - 9 } & $\mathrm{NaX}$ & $\mathrm{NiMo-X}$ & $\mathrm{NaY}$ & NiMo-Y & $\mathrm{NaM}$ & NiMo-M & UZ & NiMo-UZ \\
\hline $\mathrm{Na}_{2} \mathrm{O}$ & 16,1 & 9,9 & 11,3 & 6,25 & 7,21 & 2,6 & - & - \\
$\mathrm{Al}_{2} \mathrm{O}_{3}$ & 25,0 & 23,5 & 16,5 & 21,0 & 10,2 & 9,44 & 0,67 & 0,58 \\
$\mathrm{SiO}_{2}$ & 37,6 & 35,4 & 49,6 & 43,3 & 68,8 & 62,9 & 92,1 & 76 \\
$\mathrm{NiO}$ & - & 4,06 & - & 4,38 & - & 4,04 & - & 4,57 \\
$\mathrm{MoO}_{3}$ & - & 8,71 & - & 9,79 & - & 8,93 & - & 6,37 \\
$\mathrm{SiO}_{2} / \mathrm{Al}_{2} \mathrm{O}_{3}$ & 2,56 & 2,56 & 5,11 & 3,51 & 11,47 & 11,39 & 234 & 223 \\
\hline
\end{tabular}

silica zeolites with the $\mathrm{SiO}_{2} / \mathrm{Al}_{2} \mathrm{O}_{3}$ ratio of 2,56 and 5,11 respectively and for $\mathrm{NaM}$ this ratio is 11,47.

A comparison of the X-ray diffraction patterns of the supports and supported NiMo catalysts are shown in fig. $1-4$. A small decrease in the intensity of crystallographic reflexes characteristic of the crystalline structure of the zeolites is noted for the supported NiMo catalysts. The numerical values at the reflexes stand for the interplanar distances $d$. The X-ray diffraction patterns of the supported catalysts do not show new reflexes characteristic of the crystalline structure of the Mo and Ni species, corresponding to the interplanar distances $\mathrm{d}$, that would indicate the formation of crystallites of these groups.

A small loss of crystallinity is probably related to the destruction of supports network during the thermal treatment of the catalyst. Only in the diffraction pattern of the catalyst supported on the UZ zeolite (Fig. 4) there appears a reflex corresponding to $d=3.74$, which is characteristic of the orthorhombic structure of $\mathrm{MoO}_{3}{ }^{3}$.

A comparison of the diffraction patterns of particular zeolites and the corresponding to them NiMo catalysts
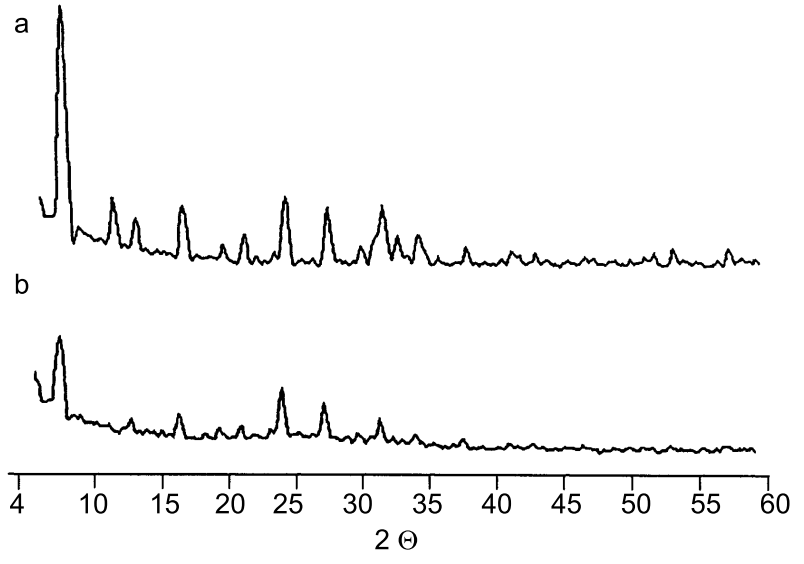

Figure 1. The XRD patterns of the blank $\mathrm{NaX}$ (a) and NiMo-X catalyst (b)

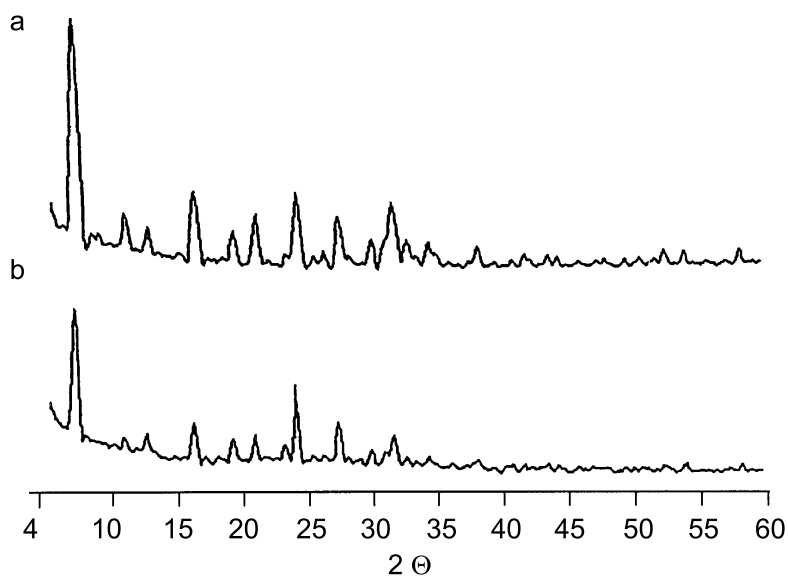

Figure 2. The XRD patterns of the blank $\mathrm{NaY}$ (a) and NiMo-Y catalyst (b)
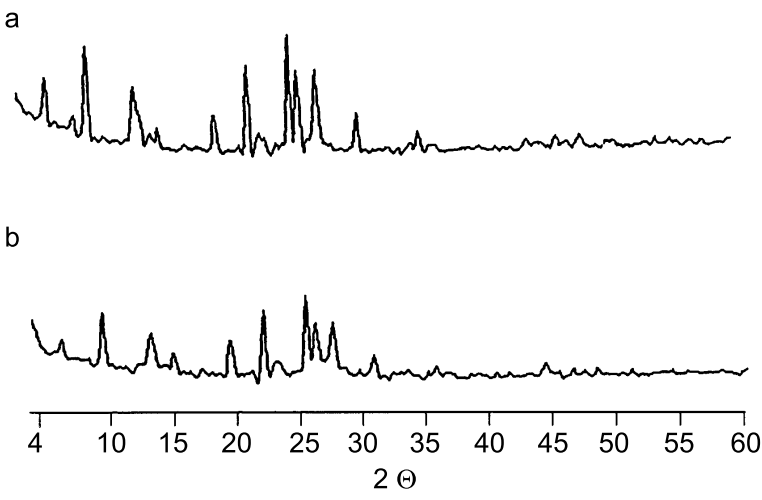

Figure 3. The XRD patterns of the blank NaM (a) and NiMo-M catalyst (b)

a
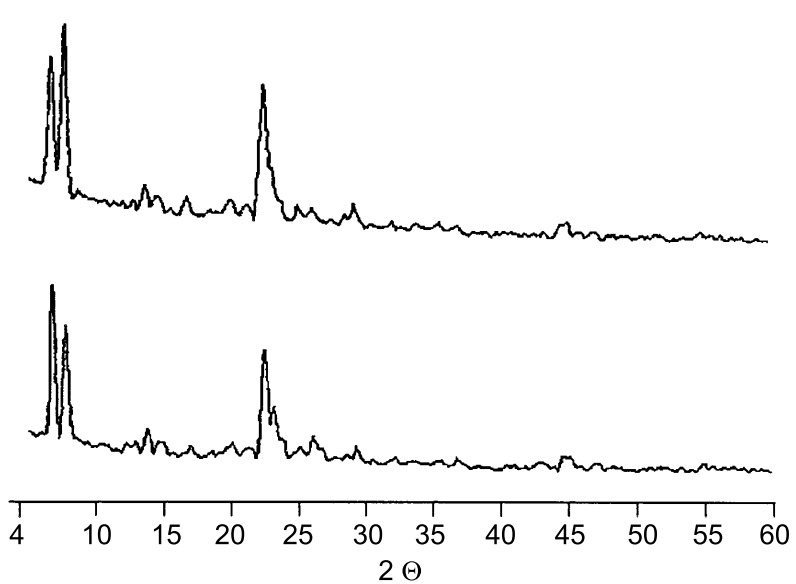

Figure 4. The XRD patterns of the blank UZ (a) and NiMoUZcatalyst (b)

has shown that after the catalysts deposition the zeolites preserved their characteristic crystalline structure and the process of impregnation with the solutions of nickel and molybdenum salts and subsequent calcination at $450^{\circ} \mathrm{C}$ caused only insignificant changes in the crystalline structure.

The analysis of the IR spectra of the zeolites and the catalysts in the range from $1400 \mathrm{~cm}^{-1}$ to $450 \mathrm{~cm}^{-1}$ (Fig. 5 -8) which covers the bands assigned to the vibrations in the $\mathrm{Al}(\mathrm{Si}) \mathrm{O}_{4}$ tetrahedra does not reveal significant shifts of the characteristic bands in the IR spectra of the catalysts that could indicate the framework destruction ${ }^{4}$.

The IR bands assigned to the structure-sensitive vibrations appearing in the $\mathrm{NaX}$ zeolite spectrum at $1005 \mathrm{~cm}^{-1}$, in the $\mathrm{NaY}$ zeolite spectrum at $1027 \mathrm{~cm}^{-1}$, in the $\mathrm{UZ}$ spectrum at $1097 \mathrm{~cm}^{-1}$ and in the $\mathrm{NaM}$ spectrum at $1060 \mathrm{~cm}^{-1}$, are shifted as a result of molybdenum deposition by 2 to 5 $\mathrm{cm}^{-1}$ and their intensity does not change. The IR spectra of the catalysts NiMo-X and NiMo-Y taken after the deposition of molybdenum show new bands at $1400 \mathrm{~cm}^{-1}$, and after the deposition of nickel also new bands at 1385 $\mathrm{cm}^{-1}$, assigned to the asymmetric vibrations support-metal. 
In the spectra of the other catalysts these bands are very weak. Zeolite supports of X and Y zeolite and NaM possess a broad IR band (not presented) in the range 3200 do $3800 \mathrm{~cm}^{-1}$ related to the presence of hydroxyl groups on the support surface,. In the spectra of the corresponding catalysts these bands are broadened and their intensity decreases, which is explained by the formation of the surface NiMo species $^{5-7}$.

A comparison of the positions and intensities of the absorption bands in the IR spectra show that the changes in these parameters are small and the structure of the catalysts remains very close to that of the relevant supports. This conclusion is consistent with the earlier conclusions following from the X-ray study implying that the procedure of the two-stage impregnation and subsequent calcination do not change much the structural properties of the supports.

Table 2 presents the surface area SBET calculated for the range of relative pressures from $\mathrm{p} / \mathrm{p}_{\mathrm{o}} 0.05$ to 0.3 ), mean pore volume and mean pore radius measured at each stage of the preparation procedure.

Table 2. Surface area, pore volume and pore size of the support and the supported NiMo catalysts

\begin{tabular}{|l|c|c|c|}
\hline Sample & $\begin{array}{c}\text { Surface area } \\
\left(\mathrm{m}^{2} / \mathrm{g}\right)\end{array}$ & $\begin{array}{c}\text { Average pore } \\
\text { volume } \\
\left(\mathrm{cm}^{3} / \mathrm{g}\right)\end{array}$ & $\begin{array}{c}\text { Average } \\
\text { pore size } \\
(\AA)\end{array}$ \\
\hline NaX & 708 & 0,34 & 19 \\
Mo-X & 567 & 0,28 & 20 \\
NiMo-X & 400 & 0,25 & 22 \\
\hline NaY & 739 & 0,35 & 9 \\
Mo-Y & 618 & 0,30 & 10 \\
NiMo-Y & 416 & 0,25 & 12 \\
\hline NaM & 229 & 0,11 & 19 \\
Mo-M & 257 & 0,13 & 20 \\
NiMo-M & 170 & 0,08 & 20 \\
\hline UZ & 275 & 0,14 & 20 \\
Mo-UZ & 265 & 0,13 & 19 \\
NiMo-UZ & 263 & 0,14 & 21 \\
\hline
\end{tabular}
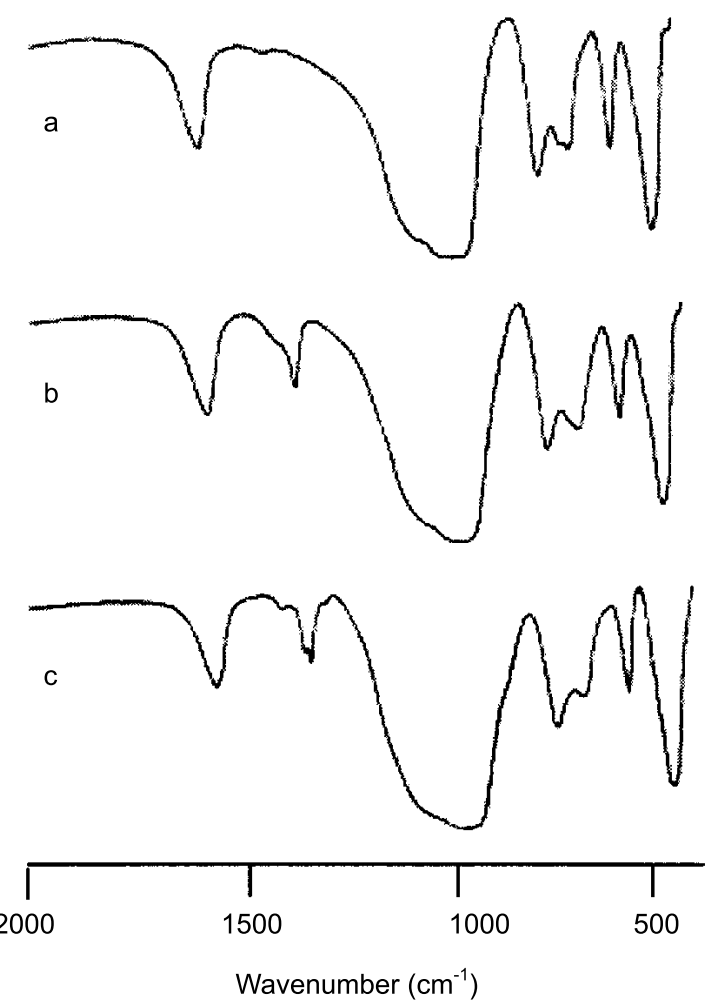

Figure 5. The IR spectra of $\mathrm{NaX}(\mathrm{a}), \mathrm{Ni}-\mathrm{X}$ (b) and NiMo$\mathrm{X}$ (c) samples

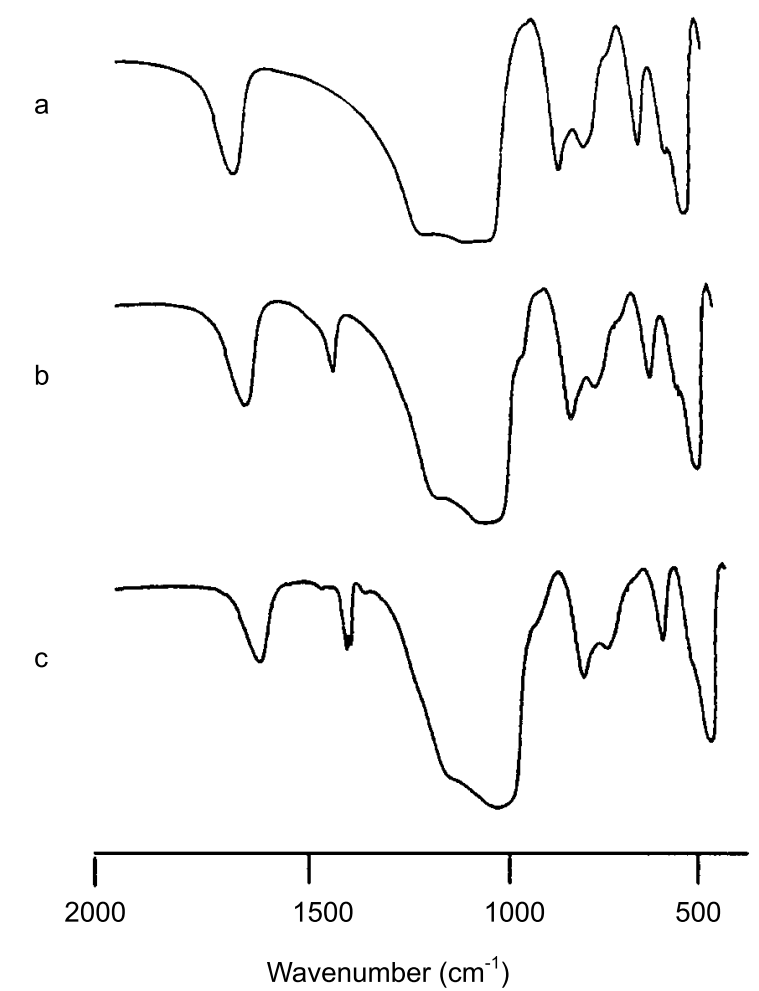

Figure 6. The IR spectra of $\mathrm{NaY}(\mathrm{a}), \mathrm{Ni}-\mathrm{Y}$ (b) and NiMoY (c) samples
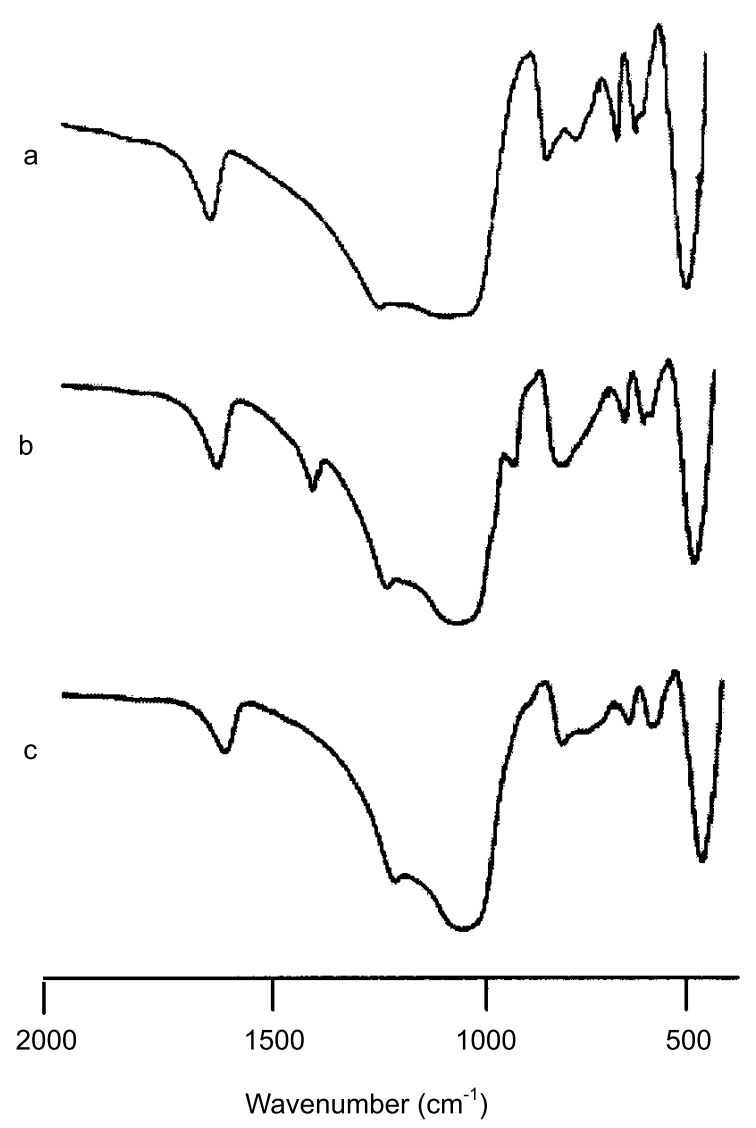

Figure 7. The IR spectra of NaM (a), Ni-M (b) and NiMoM (c) samples

The NaX and NaY zeolites have greater mean pore volume and about three times greater surface area than the UZ and NaM ones. After impregnation with $\mathrm{Ni}$ and Mo ions the surface area of $\mathrm{NaX}$ and $\mathrm{NaY}$ zeolites decreases more than $40 \%$. This means that part of cages 
a

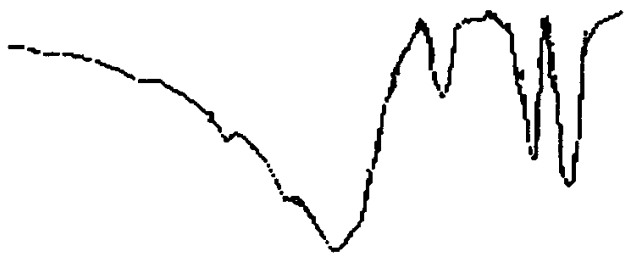

b
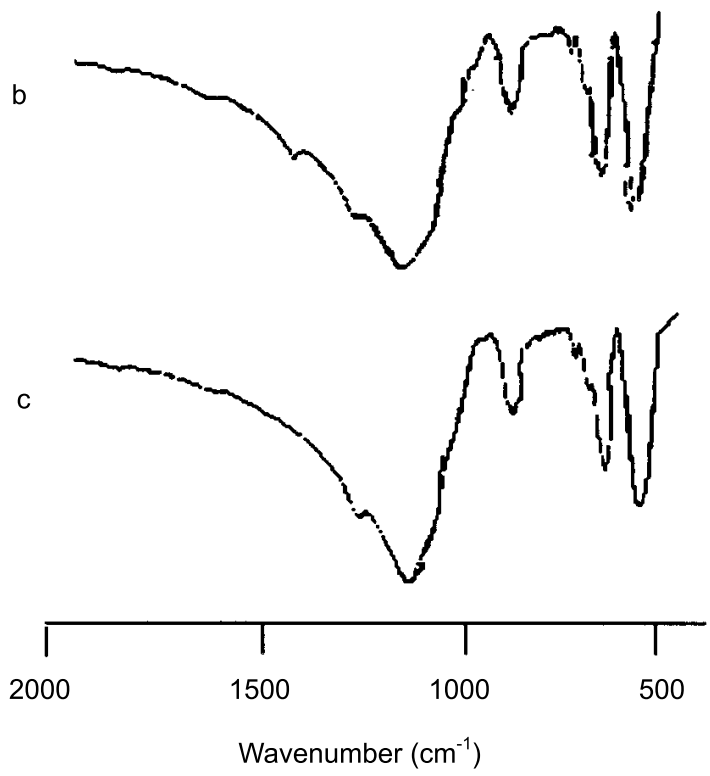

Figure 8. The IR spectra of UZ (a), Ni-UZ (b) and NiMoUZ (c) samples

becomes inaccessible to nitrogen on adsorption, probably due to zeolite windows blocking. The surface area of UZ remains almost unchanged after the impregnation with the NiMo phase, while the parameter of NaM after impregnation decreases by about $25 \%$. A decrease in the surface area does not ensue significant changes in the pore openings volume.

Figs. 9 - 12 present the isotherms of nitrogen adsorption and desorption on the initial zeolites and the NiMo catalysts. The shapes of the adsorption isotherms determined for $\mathrm{NaX}, \mathrm{NaY}$ and the $\mathrm{NaM}$ zeolite are type I according to the IUPAC classification ${ }^{8}$, an almost horizontal adsorption curve is characteristic of the ideally microporous structure. The curve obtained for UZ is classified as type I/II according to the same classification. However, this type of the curve indicates the micro- and mesoporous structure of the material.

The adsorption-desorption isotherms for all the examined initial zeolite samples show a hysteresis loop, which are of type $\mathrm{H} 4$ according to the IUPAC classification, and indicates aggregates of platy particles with slit-shaped pores in the micropore range. After the deposition of the NiMo phase and after subsequent stages of calcination the width of the hysteresis loop changes, which suggests the formation between the aggregates meopores in X and $\mathrm{Y}$ zeolites. In the case of the NiMo-UZ and the NiMo-M catalysts the widths are similar to initial zeolites

The mean pore radius and mean pore volume (Table 2) have been calculated according to the $\mathrm{BJH}$ theory from the desorption branches of the isotherms. The pore distribution according to their size is presented in Figs. 13 16. For all the catalysts the distribution of pore volume is relatively narrow. In the catalysts supported on $\mathrm{X}$ and Y zeolites the dominant ones are the pores of $48 \AA$ in

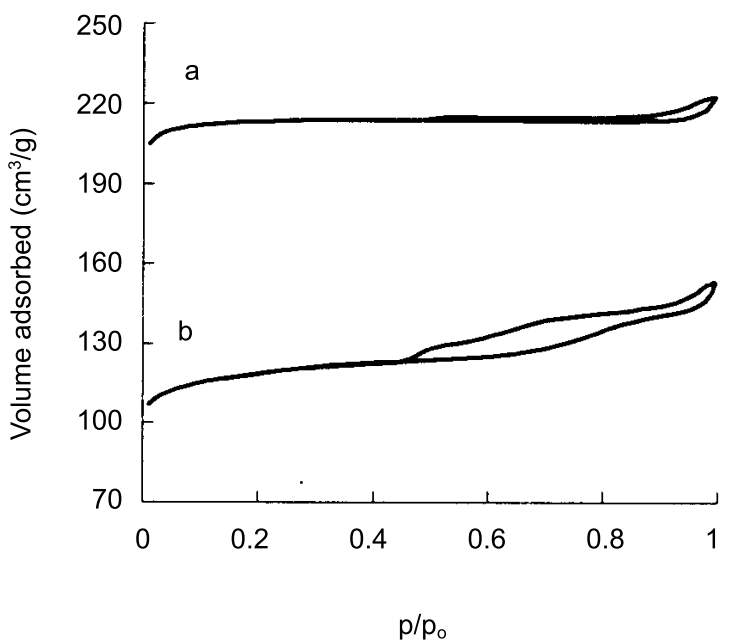

Figure 9. Nitrogen sorption isotherms for the $\mathrm{NaX}$ zeolite (a) and the NiMo-X catalyst (b)

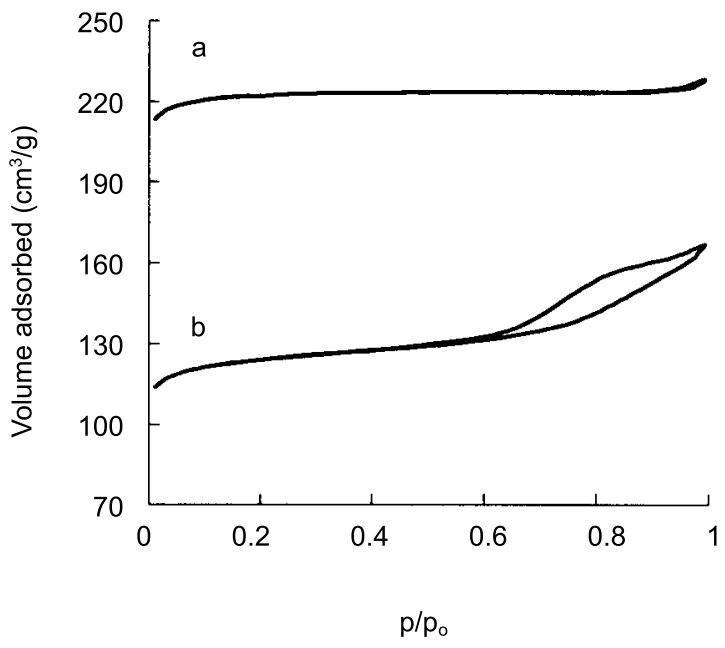

Figure 10.Nitrogen sorption isotherms for the NaY zeolite (a) and the NiMo-Y catalyst (b)

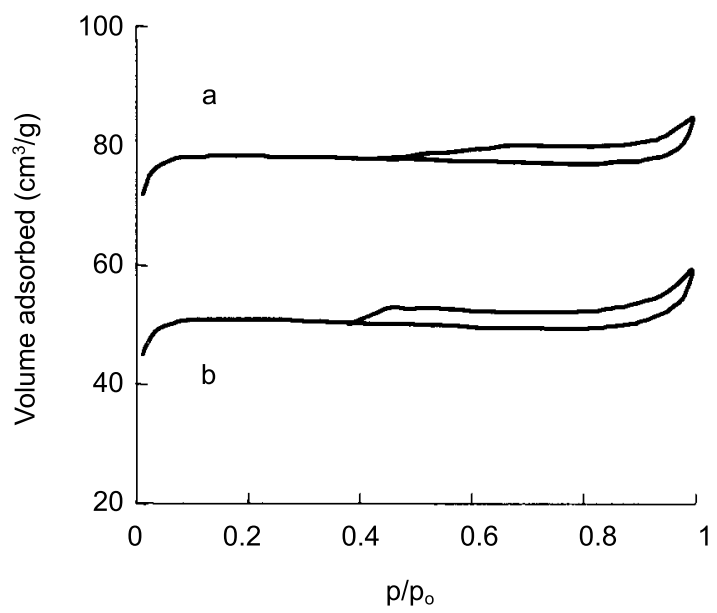

Figure 11. Nitrogen sorption isotherms of the NaM zeolite (a) and the NiMo-M catalyst (b)

diameter, in those supported on UZ and mordenite the dominant ones are channels of 38 and $45 \AA$, respectively. In the NiMo-X and NiMo-Y catalysts there are also mezopores of diameters from the range $50-100 \AA$. It means, that pores (openings) with such a width can be formed only between the particles of the samples.

The analysis of the volume of the adsorbed nitrogen calculated at the relative pressure of $\mathrm{p} / \mathrm{p}_{\mathrm{o}}=0,2$, when a 


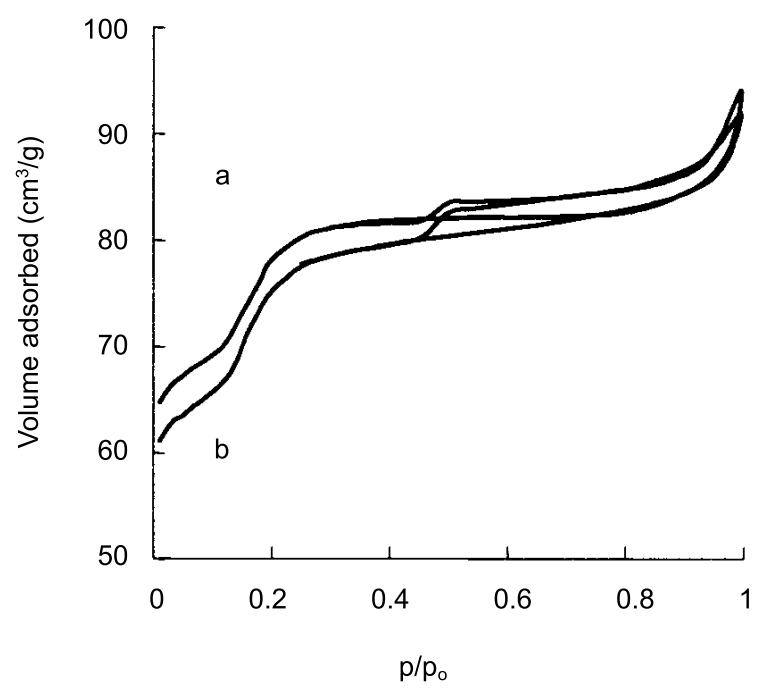

Figure 12.Nitrogen sorption isotherms of the UZ zeolite (a) and the NiMo-UZ catalyst (b)

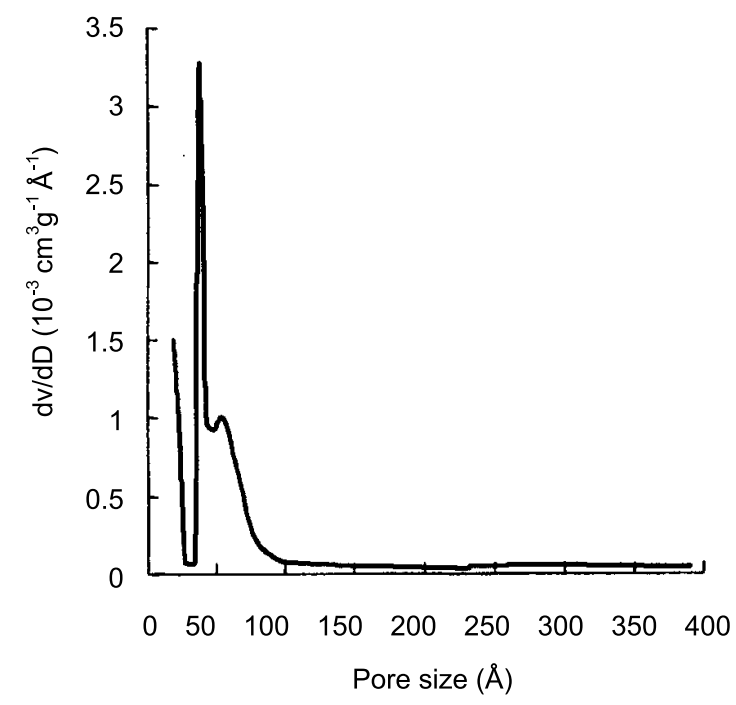

Figure 13. The pore volume distributions of the catalysts

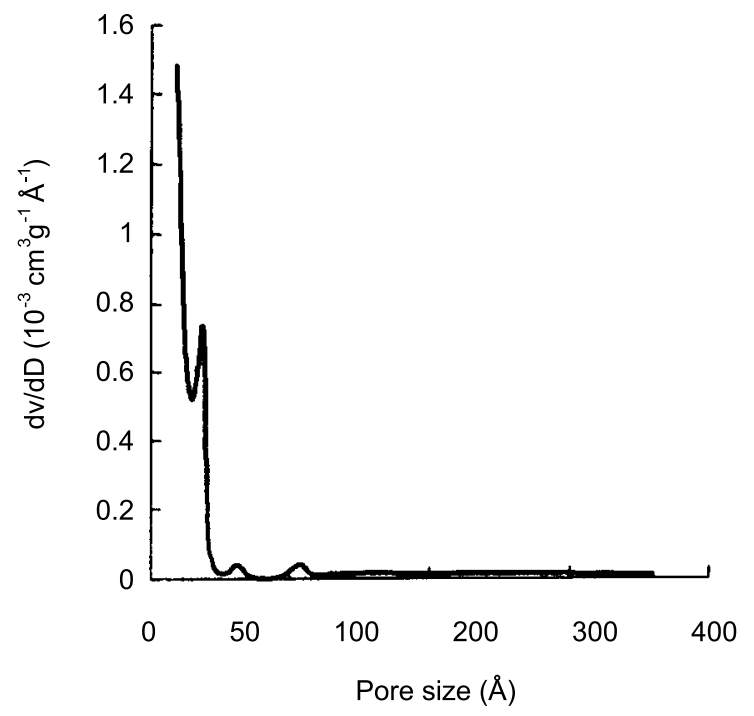

Figure 14. The pore volume distributions of the catalysts

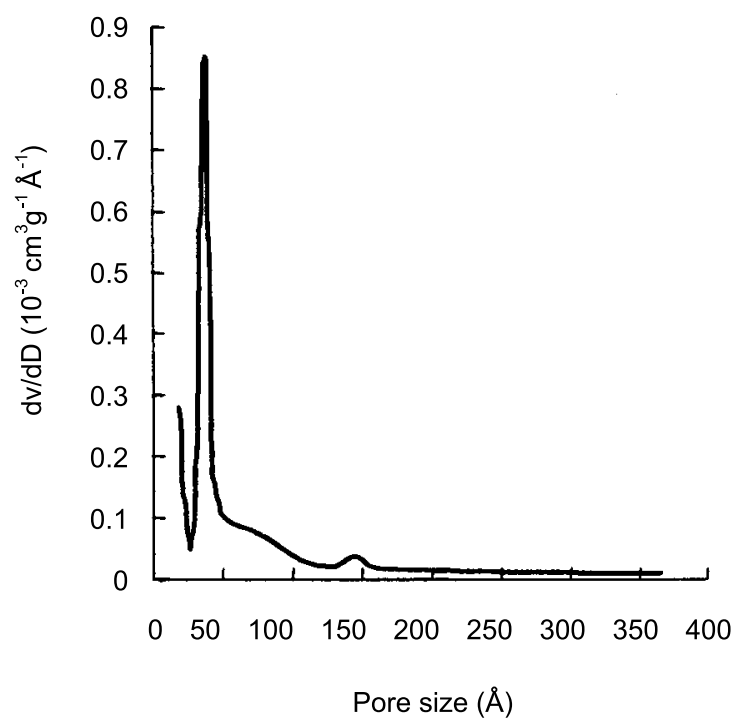

Figure 15. The pore volume distributions of the catalysts

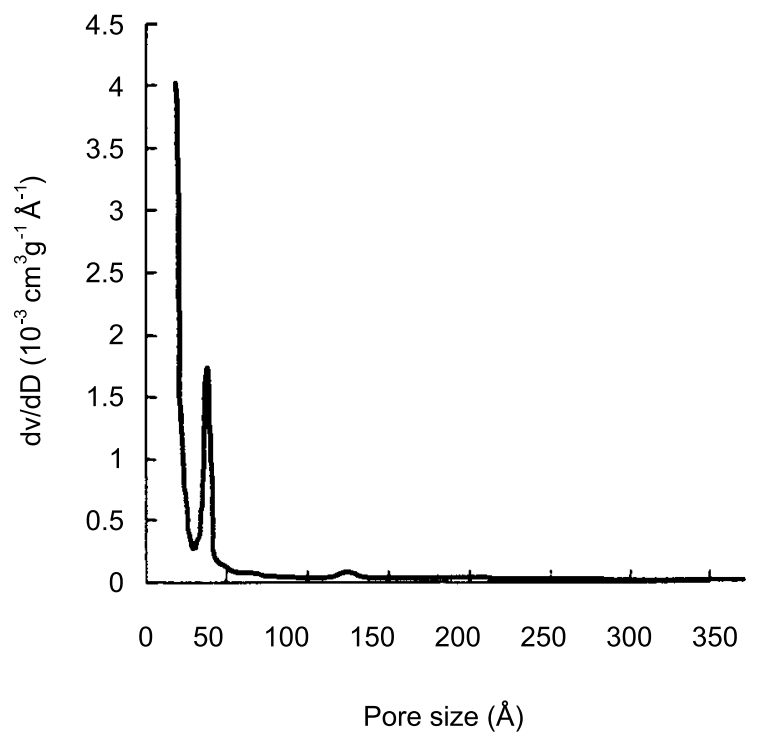

Figure 16. The pore volume distributions of the catalysts

monolayer of nitrogen is adsorbed on the pore walls, reveals that the volume significantly decreases for the supported catalysts relative to the value for supports only. This result suggests that the metal ions introduced occupy the intergrain pores (openings)in the zeolites and block the access to the channels and cages in the supports. However, for the NiMo-UZ and UZ samples the pore volume is almost the same.

The analysis of above described changes in the zeolites after impregnation provides the information that the metal ions deposit mainly on the external zeolite surfaces.

\section{CONCLUSIONS}

The NiMo catalysts supported on X, Y, mordenite and UZ zeolites using a two-stage impregnation method with the solutions of the Ni and Mo salts preserve the crystalline structure of supports. The above conclusion follows from the X-ray diffraction study and the analysis of the IR spectra in the range covering the zeolite framework vibrations recorded for the initial supports and the catalysts supported on them. The porous structure parameters 
undergo changes indicating that the ions of the metals introduced are deposited in the intergrain cavities in the zeolites and block the accessibility of some part of the channels and cages of the supports.

\section{LITERATURE CITED}

(1) Ward J. W.: Stud. Surf. Sci. and Catal., 1983, 16, 587.

(2) Valyon J., Meszaros A. K.: Zeolites; Facts, Figures, Future, Elseviere, Amsterdam, 1989, 1015.

(3) Ali M. A., Tatsumi T., Masuda T.: Appl. Catal.A, 2002, 233, 77.

(4) Ciciszwili G. W.: Zeolity naturalne, 2000, 60, 193.

(5) Beck L., Haw J. H.: J. Phys. Chem., 1995, 99, 1076.

(6) de Menorval L. C., Buckermann L. C., Figures W.: J. Phys. Chem., 1996, 100, 465.

(7) Su B., Norberg V.: Zeolites, 1997, 19, 65.

(8) IUPAC Reporting Physisorption Data, Pure Appl. Chem., 1985, 57, 603. 